\title{
Malária adquirida durante atividade entomológica na Serra do Mar, região Sudeste do Brasil*
}

\author{
Malaria acquired during entomological research undertaken on the coastal \\ range of southeastern Brazil
}

\author{
Glória Cristina Carréri-Bruno, Ricardo Mário de Carvalho Ciaravolo, Mariza Pereira
}

Superintendência de Controle de Endemias (SUCEN) - Brasil

\begin{abstract}
No inf́cio de 1993 foi detectado um foco de malária no Parque Estadual da Serra do Mar, área de Mata Altántiça no Estado de Sāo Paulo (Bresil). Quando da realizaçāo da pesquisa entomológica ocorreu a infecção malárica por Plasmodium vivax em trés capturadores da equipe de campo. A transmissão ocorreu em área que vem apresentando baixos niveis de incidência de malárla, e os capturadores tiveram um perfodo de exposiçăo extremamente reduzido. sendo de apenas tres horas em um dos casos.
\end{abstract}

Malária vivax, transmissão. Exposiçāo ocupacional. Controle de mosquitos.

O Estado de São Paulo apresentou, nos últimos dez anos, média anual de 40 casos de malária autóctone. A área de transmissão mais importante, responsável por aproximadamente $90 \%$ desses casos, está associada à Mata Atlântica, envolvendo municípios localizados nas regiōes do Litoral Norte, Baixada Santista, Vale do Ribejra e Grande São Paulo.

A Mata Atlântica, área de maior cobertura vegetal natural do Estado de São Pauló, apresenta número elevado de representantes da família Bromeliaceae ${ }^{3}$, criadouros de anofelinos do subgênero Kerteszia, responsáveis pela transmissão de malária dessa regiãos.

A malária que ocorre nessa área, cujo agente etiológico tem sido caracterizado como Plasmodium vivax na maioria dos casos apresenta baixa parasitemia, sendo freqüentes infecçōes oligossintomáticas, e até mesmo casos assintomáticos ${ }^{2}$. A transmissão ocorre geralmente de forma isolada, sem relação temporal ou espacial evidente, ou ainda em pequenos surtos 1 .

No período de 7 de janeiro a 29 de março de 1993 correu un surto de malária no Município de São Vicente ( $23^{\circ} 57^{\prime} 30^{\prime \prime}$ de latitude sul e $46^{\circ} 23^{\prime} 15^{\prime \prime}$ de longitude oeste), na Baixada Santista. Foram identificadas como área de transmissão as localidades Pai Matias e Engenheiro Ferraz, tendo sido notificados sete casos. Embora estejam em área de preservação ambiental, integrando o Parque Estadual da Serra do Mar, tais localidades apresentam pequenos desmatamentos com áreas de posse e cultivos de subsistência, e o acesso a elas é feito quase exclusivamente pela linha férrea das Ferrovias Paulistas S.A. (FEPASA), percurso Santos-Săo Paulo.

A população residente nessas localidades restringe-se a funcionários da empresa ferroviária e alguns posseiros, sendo que a área é também freqüentada por indígenas presentes na regiāo, extrativistas clandestinos e pessoas que, geralmente nos finais de semana, buscam lazer.

As casas existentes na área encontram-se dispersas na mata, sendo construçōes bastante simples, geralmente de madeira ou pau-a-pique.

A partir da deteç̧ão do primeiro caso, a Superintendência de Controle de Endemias (SUCEN), órgão responsável pelo Programa de Controle de Malária no Estado de São Paulo, desencadeou as atividades previstas para controle de foco, entre as quais captura entomológica. No

\footnotetext{
* Trabalho apresentado no XII/ Congresso Brasileiro de Parasitologia, Rio de Janeiro, 1993.

Sepataratas/Reprints: Gloria C.C. Bruno-Rua João Ramalho, 587 -11310-050-Sāo Vicente, SP - Brasil Edipá subvencionada pela FAPESP. Processo 94/0500-0.

Recebido em 19.9.1994. Aprovado em /3.1.1995.
} 
desenvolvimento desta atividade foi utilizada armadilha de Shannon em ambiente peridomiciliar. As capturas foram realizadas nos dias 17 e 25 de fevereiro e 11 de março, tendo duração de três horas cada, abrangendo o crepúsculo vespertino. Como resultado dessas pesquisas, foram obtidos 1.170 exemplares de Anopheles (Kerteszia) cruzii, única espécie de anofelino detectada. Durante essas atividades entomológicas, três funcionários, um que participou de uma captura e outros dois que participaram de duas, contraíram infecção malárica.

Todos os casos desse foco foram diagnosticados mediante técnica de gota espessa, tendo o agente etiológico apresentado características morfologicas de $P$. vivax. Nos casos dos funcionários da SUCEN foi possivel haver melhor acompanhamento, e assim verificou-se que, embora apresentassem sintomatologia compatível com infecção malárica, foram necessárias repetidas hemoscopias até a constatação parasitológi$\mathrm{ca}$, sugerindo que métodos de maior sensibilidade diagnostica devam ser empregados em áreas que apresentem semelhante perfil epidemiologico ${ }^{4}$.

O relato dos casos ora descritos é digno de nota, uma vez que a malária foi adquirida durante desempenho de atividade profissional no Estado de São Paulo, onde a incidência apresenta-se em baixos níveis. As localidades envolvidas, embora apresentem alta receptividade, têm os últimos registros de autoctonia em 1982, quando foram detectados dois casos. Anteriormente, existe notificação de um caso em 1966 e outro em 1972 Importa também ressaltar o reduzido espaço de tempo a que os capturadores estiveram expostos, sendo em um dos casos aperas três horas. Como técnica de coleta foi utilizada a armadilha de Shannon, indicada até mesmo para área endêmica, por representar menor risco de aquisiçāo de malária, quando comparada à tradicional técnica de isca humana. Apesar de existirem antigos relatos de funcionários da SUCEN que contraíram malária, nāo houve anteriormente sua divulgaçāo junto à comunidade científica.

Destaca-se a necessidade de aprofundar estuđos nessa área visando a ampliar o conhecimento sobre a dinâmica de transmissão da malária e melhor caracterização do agente etiológico.

\section{Agradecimento}

Ao Prof. Dr. Delsio Natal, do Departamento de Epidemiologia da Faculdade de Saúde Pública da Universidade de Såo Paulo, pelas sugestões apresentadas.

\section{Referências Bibliográficas}

1. ARANHA-CAMARGO, L.M. A malária autóctone do Litoral Sul do Estado de São Paulo. São Paulo, 1991. [Dissertação de Mestrado - Escola Paulista de Medicina].

2. CARVALHO, M.E.; GLASSER, C.M.; SANTOS, L.A.; CIARAVOLO, R.M.C. Nota sobre o encontro de casos autóctones de malária vivax por meio de técnica sorológica em São Paulo. Cad. Saúde Priblica, 1:250-2, 1985.

3. SÃO PAULO (Estado), Secretaria do Meio Ambiente. A Serra do Mar degradação e recuperação. São Paulo, 1990. (Série Documentos).
4. SOUZA, J. M.; BENEDITO, V. A.; SILVA, D. R; MEIRELES, R. L. Gota espessa ou QBC para o diagnóstico parasitológico específico de malária? Rev. Bras. Parasitol. Vet., 2 (2): 100 1993.

5. TLBAKI, R. M.; CARRÉRI-BRLNO, G. C.; GLASSER, C. M.; CIARAVOLO, R. M. C. Biting activity of Anopbeles (Kerteszia) cruzit (Diptera, Culicidae) in domiciliary habitats in the Southern Atlantic Forest, Peruibe, State of São Paulo, Brazil. Rev. Bras. Entomol., 37: 569-75, 1993.

6. VTTOR, M. A. M. A devastaçâo florestal. Sâo Paulo, Sociedade Brasileira de Silvicultura, s.d.

\begin{abstract}
A focus of malaria was discovered at the beginning of 1993, in the Coastel Range State Park, in the Atiantic Forest area of the State of S. Paulo. Brazil. The entomological research carried out there caused malaria infection by Plasmodium vivax in three workers of the Endemic Research Control Superintendancy (Superintendencia de Controle de Endemias - SUCEN), of the State Health Secretariat. It is worth emphasizing that transmission occurred in an area which had been presenting low levels of incidence of the disease; also, the capturers who were undertaking their entomological activities in the area were exposed for an extremely short period of time in one case for onily three hours.
\end{abstract}

Malaria, vivax, transmission. Occupational exposure. Mosquito control. 